\title{
Analysis of the Accuracy of Reconstruction of a Human Cornea by Two Geometric Modelling Techniques: A Comparative Study
}

\author{
F. J. F. Cañavate ${ }^{1}$, F. Cavas ${ }^{1}$, J. S. Velázquez ${ }^{1(\otimes)}$, J. M. Bolarín ${ }^{2}$, and J. L. Alió ${ }^{3}$ \\ ${ }^{1}$ Department of Structures, Construction and Graphical Expression, Technical University of \\ Cartagena, 30202 Cartagena, Spain \\ jose.velazquez@upct.es \\ 2 Technology Centre for IT and Communications (CENTIC), Scientific Park of Murcia, \\ 30100 Murcia, Spain \\ ${ }^{3}$ Division of Ophthalmology, Miguel Hernández University, 03690 Alicante, Spain
}

\begin{abstract}
This study compares two techniques of reconstruction and representation of the anterior and posterior surfaces of the human cornea, both for healthy and for keratoconus eyes, in a CAD software environment using raw tomographic data, by two different methods: a mesh model (obtained from a grid of points) and a NURBS surface model. After reconstruction, a morpho-geometric analysis was made, and several parameters were defined and measured in a set of 100 healthy eyes and 61 keratoconus eyes, detecting the statistical analysis significant differences between methods for both groups. Mesh method proved to be more accurate, but less eyes could be modelled. Volumetric and surface measurement values showed a total equivalence between both methods, so these would be the ones to use when modelling eyes for keratoconus detection and characterization purposes.
\end{abstract}

Keywords: NURBS $\cdot$ Scheimpflug tomography $\cdot$ Computer-aided design $\cdot$ Point cloud $\cdot$ Cornea

\section{Introduction}

Geometric modelling allows the representation of a physical shape from a discrete cloud of scanned points [1], being currently used for a wide variety of engineering applications, such as reconstruction of 3D urban models [2], geo-morphometry assessment [3], design parametrization in reverse engineering [4], prosthesis production [5] or rare disease diagnosis [6], among others.

In addition, the use of CAD tools in biological structure modelling is a well-stablished technique that allows creating both virtual and printed 3D models [7]. However, not much attention has been paid to which technique fits better the geometrical reconstruction, and how this affects clinical diagnosis.

Many commercial tools with auto-surfacing capabilities can easily convert point clouds into surface models [4], but the reconstruction methods are not unique, and the accuracy of the results may vary depending on which method is selected. Usual 
alternatives are using a "mesh" model (obtained from a grid of points) or a "patch" model based in non-uniform rational basis splines (NURBS).

Meshes have no topological constraints and have a simple definition [8], but they are discrete and therefore performing operations with them can be difficult [9]. NURBS are a mathematical model commonly used in CAD environments for generating and representing curves and surfaces [10]. They are parametrically defined, and therefore, they are smooth no matter the scale, and operations such as intersection or trimming can be simpler because coordinates can be calculated anywhere on the surface. However, maths involved are difficult and therefore data exchange with other 3D applications is almost impossible [9].

This study presents a comparative analysis of two reconstruction and representation techniques applied to the anterior and posterior surfaces of the human cornea, for both healthy eyes and eyes with keratoconus (KC), to assess the strengths and weaknesses of each representation in $\mathrm{KC}$ disease detection.

\section{Materials and Methods}

\subsection{Geometrical Reconstruction of the Human Cornea}

In this research, we have reconstructed both anterior and posterior corneal surfaces from the raw tomographic data (unprocessed by the device software, which avoids possible biases) generated by the corneal tomographer Sirius ${ }^{\circledR}$ (CSO, Italy) in the form of two clouds of points. To do so, we used the surface-handling CAD software Rhinoceros ${ }^{\circledR} \mathrm{V}$ 5.0 (MCNeel \& Associates, Seattle, USA), which offered two alternative reconstruction methods, between which we wanted to compare:

- "Patch" surface generation function. Uses a NURB surface to reconstruct both corneal surfaces, minimizing the nominal distance between the 3D point cloud and the solution surface. A cubic NURB surface was used with a segmentation of 256 in each parametric direction. The surface so obtained, approximates the point cloud.

- "Mesh" model to generate a grid. In this case, the points lie on each surface, and then surfaces are obtained by interpolation. A rectangular grid of 21 rows and 256 columns was selected, being then deformed to minimise the nominal distance between the spatial points and the grid surface.

Rhinoceros ${ }^{\circledR}$ "PointDeviation" function was used to estimate the mean distance error between the generated surface and the cloud of points used for its generation. For both surface generation methods, and for both anterior and posterior surfaces, a threshold limit of $10^{-3}$ was fixed to consider the points as "not valid", while a value of $10^{-4}$ was considered a "good" point. Eyes with a mean value of error for all their points lower than $5 \times 10^{-3}$ were discarded from the original set.

The procedure followed to generate full 3D customized corneal models consisted in two stages (Fig. 1): a first one of virtual 3D modelling of the cornea, in which corneal tomography system acquires the altimetry data of the corneal surfaces, that is later exported to Rhinoceros ${ }^{\circledR}$ to reconstruct the surface by the two methods previously exposed; and a second one of morpho-geometric analysis, in which the customized 

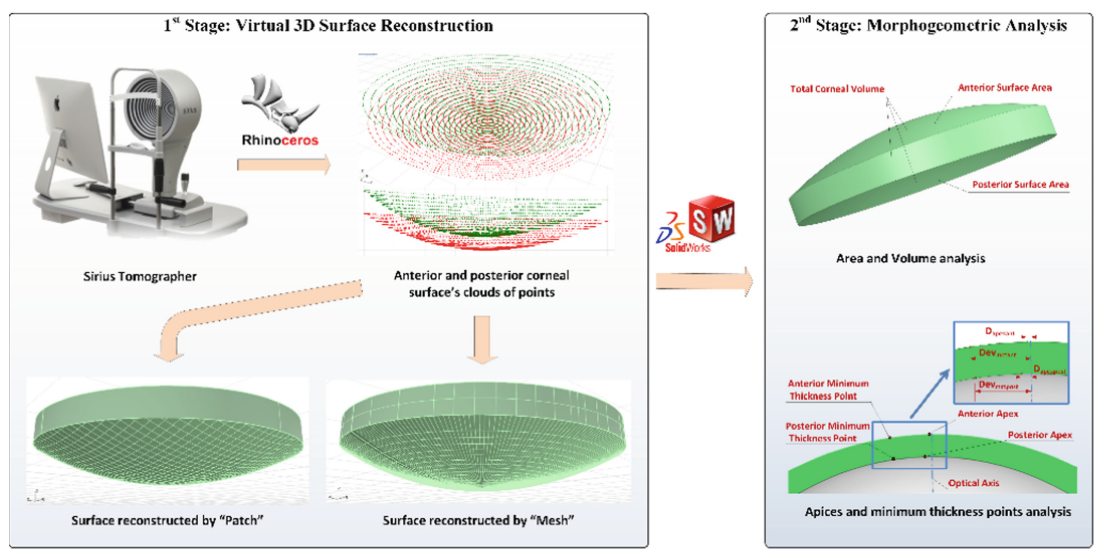

Fig. 1. Customized corneal model reconstruction procedure

3D corneal model obtained in Rhinoceros ${ }^{\circledR}$ was transferred to the CAD/CAM program SolidWorks® V 2015 (Dassault Systèmes, Vélizy-Villacoublay, France), that allowed performing a thorough analysis of the custom model and therefore characterizing its morpho-geometry.

The final output after this stage, was the set of thirteen parameters related with area and volume shown in Table 1. These parameters, which have been described in detail in a precedent study [11], were finally studied in a specific set of eyes, in order to determine which reconstruction method characterized better $\mathrm{KC}$.

\subsection{Practical Application}

This comparative study included 161 eyes of 161 patients selected at random from the official database "Iberia" of KC cases (RETICS-OFATARED).

The sample was later divided into two groups: a "healthy" group formed by 100 healthy eyes of 100 individuals, and a "keratoconus" group that included $61 \mathrm{KC}$ eyes of 61 patients. The presence and degree of the disease was stablished according to state-of-the-art evaluation techniques and the Amsler-Krumeich classification [12], creating subgroups for the Grades I (27 subclinical KC eyes) and II + III + IV (34 clinical KC eyes).

The research was developed at Vissum Corporation Clinic in Alicante, Spain, and was ratified by the institution's Ethical Board, according to the tenets the Declaration of Helsinki (7th revision, October 2013, Fortaleza, Brazil). An agreed consent form was signed by each participant.

\subsection{Statistical Analysis}

The software used to perform all statistical analyses was SPSS V23.0 (IBM, Armonk, EEUU). To check the normality of data, Kolmogorov-Smirnov test and Shapiro-Wilks test were used. To determine if the measured values of the morpho-geometric parameters 
depended on the function used when reconstructing the corneal surface ("mesh" or "patch"), Student and Mann-Whitney tests for unpaired data were used. A significance level of 0.05 was fixed for p-values in all statistical tests. Bland-Altman diagrams were used with comparison purposes.

Table 1. Difference in value and statistical significance of "patch" vs. "mesh" functions comparison for each morpho-geometrical parameter. Stu.: Student's test p-value; Wilc.; Wilcoxon's test p-value; Abs.: Absolute difference in value; \%: Relative difference in percentage.

\begin{tabular}{|c|c|c|c|c|c|c|c|c|}
\hline \multirow[t]{2}{*}{ Parameter (unit) } & \multicolumn{2}{|c|}{ Difference } & \multicolumn{2}{|c|}{ Healthy $(\mathrm{n}=89)$} & \multicolumn{2}{|c|}{ Grade $\mathrm{I}(\mathrm{n}=24)$} & \multicolumn{2}{|c|}{$\begin{array}{l}\text { Grade II + III + IV ( } \mathrm{n}= \\
18)\end{array}$} \\
\hline & Abs & $\%$. & Stu. & Wilc. & Stu. & Wilc. & Stu. & Wilc. \\
\hline $\begin{array}{l}\text { Total volume } \\
\left(\mathrm{mm}^{3}\right)\end{array}$ & 0.04 & 0.16 & 0.049 & 0.043 & 0.233 & 0.383 & 0.873 & 1.000 \\
\hline $\begin{array}{l}\text { Ant. Apex area } \\
\left(\mathrm{mm}^{2}\right)\end{array}$ & 0.05 & 0.08 & $<0.001$ & $<0.001$ & 0.025 & 0.041 & 0.178 & 0.183 \\
\hline $\begin{array}{l}\text { Post. Apex area } \\
\left(\mathrm{mm}^{2}\right)\end{array}$ & 0.02 & 0.03 & $<0.001$ & $<0.001$ & 0.026 & 0.003 & 0.152 & 0.197 \\
\hline Total area $\left(\mathrm{mm}^{2}\right)$ & 0.04 & 0.03 & 0.015 & 0.061 & 0.443 & 0.603 & 0.553 & 0.875 \\
\hline $\begin{array}{l}\text { Sag. plane apex } \\
\text { area }\left(\mathrm{mm}^{2}\right)\end{array}$ & 0.04 & 0.93 & 0.373 & 0.419 & 0.875 & 0.692 & 0.029 & 0.018 \\
\hline $\begin{array}{l}\text { Sag. plane area at } \\
\text { MTP }\left(\mathrm{mm}^{2}\right)\end{array}$ & 0.02 & 0.39 & 0.033 & 0.161 & 0.655 & 0.534 & 0.862 & 0.409 \\
\hline $\begin{array}{l}\text { Ant. apex dev. } \\
(\mathrm{mm})\end{array}$ & 0.03 & 482.7 & 0.008 & 0.011 & 0.086 & 0.005 & 0.001 & 0.001 \\
\hline $\begin{array}{l}\text { Post. apex dev. } \\
(\mathrm{mm})\end{array}$ & 0.10 & 92.37 & 0.786 & $<0.001$ & 0.063 & 0.064 & 0.464 & 0.084 \\
\hline $\begin{array}{l}\text { Centre of mass X } \\
(\mathrm{mm})\end{array}$ & 0.00 & 8.69 & 0.006 & 0.009 & 0.417 & 0.405 & 0.773 & 0.671 \\
\hline $\begin{array}{l}\text { Centre of mass } Y \\
(\mathrm{~mm})\end{array}$ & 0.00 & 12.37 & 0.013 & 0.005 & 0.271 & 0.3 & 0.11 & 0.127 \\
\hline $\begin{array}{l}\text { Centre of mass } Z \\
(\mathrm{~mm})\end{array}$ & 0.00 & 7.47 & 0.841 & 0.85 & 0.05 & 0.052 & 0.856 & 0.829 \\
\hline $\begin{array}{l}\text { Ant. MTP } \\
\text { deviation (mm) }\end{array}$ & 0.16 & 16.62 & 0.077 & 0.045 & 0.729 & 0.966 & 0.184 & 0.245 \\
\hline $\begin{array}{l}\text { Post. MTP } \\
\text { deviation (mm) }\end{array}$ & 0.16 & 17.81 & 0.125 & 0.014 & 0.796 & 0.853 & 0.374 & 0.889 \\
\hline
\end{tabular}

\section{Results}

Table 1 shows the result of the comparison between both methods. For each case, it was studied if the difference between the values measured by both methods was different from zero (meaning zero total equivalence between them). As shown, significant differences were found between them when considering the total number of eyes, and also for each grade of the disease.

It is important to highlight that not all the corneas (161) could be reconstructed from the cloud of points. Some of them did not lead to any result at all when treated with Rhinoceros ${ }^{\circledR}$, and some others showed values of the mean deviation error from the cloud of points to the final surface higher than $10^{-3}$, which invalidated them for the study. Table 2 summarizes how each function performed. 
Table 2. Distribution and total number of cases successfully modelled by each function

\begin{tabular}{l|l|l|l}
\hline & Healthy & Keratoconus & Total \\
\hline Total raw data & 100 & 61 & 161 \\
\hline Total modelled & & & \\
\hline Grid & $89(89 \%)$ & $42(69 \%)$ & $131(81 \%)$ \\
\hline Patch & $96(96 \%)$ & $56(92 \%)$ & $152(94 \%)$ \\
\hline
\end{tabular}

\section{Conclusions}

Results in Table 1 indicate that both methods are not equivalent, especially when measuring the anterior/posterior apices and anterior/posterior minimum thickness points deviations. The lack of concordance between methods for posterior apex deviation (92\% difference) is of paramount importance, as this is considered the critical parameter for early $\mathrm{KC}$ detection [13]. The difference for anterior apex deviation is even higher (482.73\%), but as anterior apex starts to displace in most advanced stages of the disease [14] and disease can be diagnosed by other parameters at this stage, this difference is less important.

According to Table 2, the use of "patch" function allows modelling a higher amount of corneal surfaces not only for healthy eyes but also for $\mathrm{KC}$ ones. Its main drawback is the tolerance or approximation to the cloud of points, which makes it less sensible for modelling $\mathrm{KC}$ at a local level in its early stages than the "mesh" function. Conversely, the degree of precision with "mesh" function is higher, and therefore the approximation to the cloud of points is better, but its main downside is that a great number of $\mathrm{KC}$ corneas could not be modelled. When the surface is very abrupt, or highly steeped (advanced stage of the KC pathology) such a sensible method of surface reconstruction like "mesh" presents local reconstruction problems that lead to non-convergence, which could be used as a clue of presence of the disease.

Funding. This publication forms part of the Thematic Network for Co-Operative Research in Health (RETICS), reference number RD16/0008/0012, financed by the Carlos III Health Institute - General Subdirection of Networks and Cooperative Investigation Centers (R\&D\&I National Plan 2013-2016) and European Regional Development Funds (FEDER), and the Results Valorisation Program (PROVALOR-UPCT) financed by the Technical University of Cartagena.

\section{References}

1. Berger, M., Tagliasacchi, A., Seversky, L., Alliez, P., Levine, J., Sharf, A., Silva, C.: State of the art in surface reconstruction from point clouds. In: Eurographics 2014 - State of the Art Reports, Strasbourg, France, vol. 1, pp. 161-185, 07 April 2014. https://doi.org/10.2312/egst. 20141040.https://hal.inria.fr/hal-01017700/document

2. Wang, R., Peethambaran, J., Chen, D.: LiDAR point clouds to 3-D urban models : a review. IEEE J. Sel. Topics Appl. Earth Obs. Remote Sens. 11(2), 606-627 (2018). https://doi.org/ 10.1109/JSTARS.2017.2781132 
3. Eltner, A., Kaiser, A., Castillo, C., Rock, G., Neugirg, F., Abellán, A.: Image-based surface reconstruction in geomorphometry-merits, limits and developments. Earth Surf. Dyn. 4(2), 359-389 (2016). https://doi.org/10.5194/esurf-4-359-2016

4. Chang, K.-H., Chen, C.: 3D shape engineering and design parameterization. Comput. Aid. Des. Appl. 8(5), 681-692 (2011). https://doi.org/10.3722/cadaps.2011.681-692

5. Vukašinović, N., Kolšek, T., Duhovnik, J.: Case study - surface reconstruction from point clouds for prosthesis production. J. Eng. Des. 18(5), 475-488 (2007). https://doi.org/10.1080/ 09544820701403805

6. Cavas-Martínez, F., Fernández-Pacheco, D.G., Cañavate, F.J.F., Velázquez-Blázquez, J.S., Bolarín, J.M., Alió, J.L.: Study of morpho-geometric variables to improve the diagnosis in keratoconus with mild visual limitation. Symmetry 10, 306 (2018). https://doi.org/10.3390/ sym 10080306

7. Lohfeld, S., Barron, V., McHugh, P.E.: Biomodels of bone: a review. Ann. Biomed. Eng. 33(10), 1295-1311 (2005). https://doi.org/10.1007/s10439-005-5873-x

8. Wittek, A., Grosland, N.M., Joldes, G.R., Magnotta, V.: Miller KJAobe from finite element meshes to clouds of points: a review of methods for generation of computational biomechanics models for patient-specific applications. Ann. Biomed. Eng. 44(1), 3-15 (2016)

9. Rutten, D.: Mesh or surface, understanding the difference. Available via McNeel Rhinoceros Forums. https://discourse.mcneel.com/t/mesh-or-surface-understanding-the-dif ference/75151. Accessed 13 Jan 2020

10. Dimas, E., Briassoulis, D.: 3D geometric modelling based on NURBS: a review. Adv. Eng. Softw. 30(9), 741-751 (1999). https://doi.org/10.1016/S0965-9978(98)00110-0

11. Bolarín, J.M., Cavas, F., Velázquez, J.S., Alió, J.L.: A machine-learning model based on morphogeometric parameters for RETICS disease classification and GUI development. Appl. Sci. 10, 1874 (2020). https://doi.org/10.3390/app10051874

12. Krumeich, J.H., Daniel, J., Knulle, A.: Live-epikeratophakia for keratoconus. J. Cataract Refract. Surg. 24(4), 456-463 (1998). https://doi.org/10.1016/s0886-3350(98)80284-8

13. Cavas-Martinez, F., Fernandez-Pacheco, D.G., Canavate, F.J.F., Velazquez-Blazquez, J.S., Bolarin, J.M., Tiveron, M., Alio, J.L.: Early keratoconus detection by patient-specific 3D modelling and geometric parameters analysis. Dyna 94, 171-175 (2019). https://doi.org/10. 6036/8895

14. Velázquez, J.S., Cavas, F., Alió del Barrio, J., Fernández-Pacheco, D.G., Alió, J.: Assessment of the association between In Vivo corneal morphogeometrical changes and keratoconus eyes with severe visual limitation. J. Ophthalmol. 2019, 7 (2019). https://doi.org/10.1155/2019/ 8731626

Open Access This chapter is licensed under the terms of the Creative Commons Attribution 4.0 International License (http://creativecommons.org/licenses/by/4.0/), which permits use, sharing, adaptation, distribution and reproduction in any medium or format, as long as you give appropriate credit to the original author(s) and the source, provide a link to the Creative Commons license and indicate if changes were made.

The images or other third party material in this chapter are included in the chapter's Creative Commons license, unless indicated otherwise in a credit line to the material. If material is not included in the chapter's Creative Commons license and your intended use is not permitted by statutory regulation or exceeds the permitted use, you will need to obtain permission directly from the copyright holder. 